\section{Kompartiment eines Pharmakons}

C. Vidal ${ }^{1}$ und W.-R. Külpmann ${ }^{2}$

${ }^{1}$ Landeskriminalamt Niedersachsen, Dezernat 53 „Chemie“, Hannover, Deutschland

${ }^{2}$ Hannover, Deutschland

\section{Englischer Begriff compartment}

Definition Hypothetischer Raum im Organismus, der durch ein Volumen charakterisiert ist.

Beschreibung Ein Kompartiment ist Teil eines pharmakokinetischen Modells, das benutzt wird, um mathematisch die Änderungen der Plasmakonzentration eines Pharmakons in Abhängigkeit von der Zeit zu erfassen. Es gibt Ein-, Zwei- und
Mehr-Kompartiment-Modelle. Beim Ein-KompartimentModell wird angenommen, dass sich die Substanz augenblicklich gleichmäßig auf alle Körpergewebe verteilt. Das Zwei-Kompartiment-Modell geht von zwei (hypothetischen) Räumen aus, einem zentralen Kompartiment und einem peripheren. Bei Applikation verteilt sich der Arzneistoff rasch im zentralen Kompartiment, während sich mit dem peripheren Kompartiment sehr viel langsamer ein Gleichgewicht einstellt. „Tiefe“ Kompartimente sind Räume, in die das Pharmakon noch viel langsamer eindringt, die es aber auch viel langsamer verlässt, z. B. Liquor, Pleuraflüssigkeit, Aszites.

\section{Literatur}

Taylor WJ, Diers Caviness MH (1986) A textbook for the clinical application of therapeutic drug monitoring. Abbott, Irving 